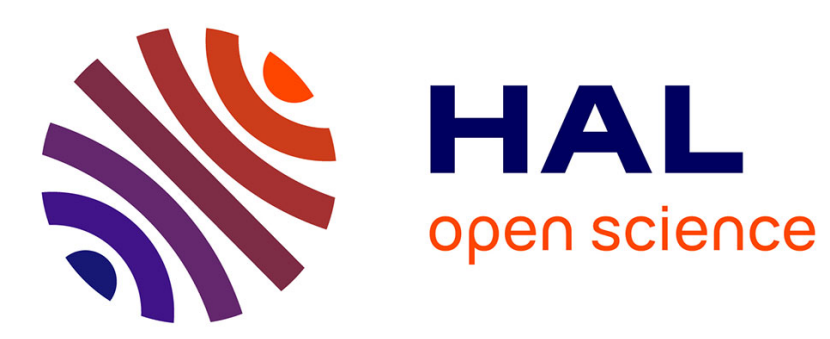

\title{
Fresh behavior of mortar based on recycled sand - Influence of moisture condition
}

\author{
Thang Le, Sébastien Rémond, Gwenn Le Saout, Eric Garcia-Diaz
}

\section{To cite this version:}

Thang Le, Sébastien Rémond, Gwenn Le Saout, Eric Garcia-Diaz. Fresh behavior of mortar based on recycled sand - Influence of moisture condition. Construction and Building Materials, 2016, 106, pp.35-42. 10.1016/j.conbuildmat.2015.12.071 . hal-02497746

\section{HAL Id: hal-02497746 \\ https://hal.mines-ales.fr/hal-02497746}

Submitted on 9 Mar 2020

HAL is a multi-disciplinary open access archive for the deposit and dissemination of scientific research documents, whether they are published or not. The documents may come from teaching and research institutions in France or abroad, or from public or private research centers.
L'archive ouverte pluridisciplinaire HAL, est destinée au dépôt et à la diffusion de documents scientifiques de niveau recherche, publiés ou non, émanant des établissements d'enseignement et de recherche français ou étrangers, des laboratoires publics ou privés. 


\title{
Fresh behavior of mortar based on recycled sand - Influence of moisture condition
}

\author{
Le Thang $^{\mathrm{a}, \mathrm{b}, *}$, Rémond Sébastien ${ }^{\mathrm{a}}$, Le Saout Gwenn ${ }^{\mathrm{b}}$, Garcia-Diaz Eric ${ }^{\mathrm{b}}$ \\ ${ }^{a}$ LGCgE-GCE, École des Mines de Douai, 59508 Douai, France \\ ${ }^{\mathrm{b}}$ C2MA, École des Mines d'Alès, 30100 Alès, France
}

\section{H I G H L I G H T S}

- Water absorption of coarse fractions of recycled sand can be measured correctly.

- Water absorption of finer fractions can be measured by an indirect method.

- Initial moisture content of recycled sand strongly affect mortar's workability.

\section{A B S T R A C T}

Recycled Concrete Aggregates (RCA) are composed of a mixture of natural aggregates more or less coated by hardened cement paste. The latter has a high capacity of water absorption. In concrete, amount of water present in the cement paste, excluding the water absorbed by aggregates, (called effective water - $W_{\text {eff }}$ ) strongly influences the fresh and hardened properties of the material. This amount of water is highly dependent on the water absorbed by the aggregates during mixing, particularly for very porous aggregates which possess large water absorption as RCA. However, the amount of water absorbed depends itself on the initial state of saturation of aggregates. The aim of this work is firstly to measure the water absorption coefficient of recycled sand (RS) by different methods, then to study the influence of moisture condition of RS on the fresh behavior of mortar. Standard (EN 1097-6) and non-standard (IFSTTAR $\mathrm{N}^{\circ} 78$, Extrapolation) methods are used in this work to measure the water absorption of RS. The results show that the water absorption closely depends on the experimental protocol used. The workability of mortars containing RS prepared in different saturation states is then measured with the Concrete Equivalent Mortar (CEM) cone. We show that initial water content, pre-saturation method and pre-saturation time significantly influence the initial workability of mortars.

\section{Keywords:}

Recycled concrete aggregate

Water absorption

Workability

Effective water

Saturation state

\section{Introduction}

The construction sector is a major consumer of natural resources and also generates a large amount of demolition wastes. Directive 2008/98/EC of the European Union sets the target of recycling at least 70\% for construction and demolition wastes by 2020 [1]. Recycled concrete aggregates (RCA) have the potential to replace natural aggregates but the influences of the material on the final concrete properties have to be studied [2]. RCA consist of a mixture of natural aggregates and adherent hardened cement paste. The latter is generally more porous than natural aggregates. Its content and physicochemical properties significantly influence

\footnotetext{
* Corresponding author at: LGCgE-GCE, École des Mines de Douai, 59508 Douai, France.

E-mail address: thang.le.esct@gmail.com (T. Le).
}

the behavior of concretes containing RCA [3,4]. Previous studies have shown that the cement paste content is decreasing with the increase in particle size of RCA [3,5,6].

Coarse RCA $\left(d_{\min }>5 \mathrm{~mm}\right)$, which generally contain a low cement paste content, have already been successfully used to replace natural gravel in concrete. The potential advantages and also disadvantages of using coarse RCA in concrete are well studied in the literature [5,7-9]. Many parameters may influence the strength of concrete as the type of RCA, the replacement amount of natural aggregates by the RCA and the saturation state of RCA $[5,10-17,18]$. According to Poon et al. [11], the state of saturation of coarse RCA significantly influences the behavior of fresh concrete. Among the studied concretes, concrete containing dry coarse RCA has a larger slump and faster workability drop than that of oversaturated coarse RCA. Moreover, the concrete containing dry 
RCA has a greater compressive strength than that of oversaturated RCA for a given effective water content and type of RCA.

Recycled sands $\left(D_{\max }<5 \mathrm{~mm}\right)$, which possess a higher cement paste content, were also used to replace natural sands in mortar or concrete. Some studies have shown that the replacement rate of recycled sand could reach $30 \%$ without significantly affecting the mechanical properties of concrete $[19,20]$. However, according to other authors [21-24], recycled sands significantly alter the properties of mortars due to a large water absorption coefficient and a high content of hardened cement paste.

In order to better control the fresh and hardened properties of mortars and concretes containing RCA, the effective water has to be determined accurately. Effective water is the water present in the cement paste of concrete or mortars, excluding the water that is absorbed by aggregates. An accurate measurement of water absorption of recycled sand is therefore needed to formulate concrete. However until now, there is no efficient method for this measurement, and several experimental procedures have been carried out in order to assess the water absorption of RCA [25,26]. Furthermore, the influence of the saturation state of aggregates on the fresh behavior of concrete containing RCA remains unclear.

The objective of this work is twofold. Firstly we aim at testing and comparing different methods of measurement of water absorption of recycled sands. Then we study the influence of the initial state of saturation, pre-saturation mode and pre-saturation time of recycled sand on the fresh behavior of mortars.

\section{Materials and methodology}

\subsection{Water absorption of recycled sand}

The sand used in this study is the recycled sand $(0 / 4 \mathrm{~mm})$ provided by the French national project Recybeton, noted RS in the following. This recycled sand comes from the DLB platform (Dock Limeil-Brévannes) of Gonesse (France). The particle size distribution is shown in Fig. 1.

The water absorption coefficient of the recycled sand (RS) is measured by different methods: the standard method EN 1097-6 [27], the IFSTTAR method №78 [28], and the method by extrapolation proposed by Zhao et al. [3].

\subsubsection{Standard method EN 1097-6}

In standard method EN 1097-6, the sample is firstly saturated in water for $24 \mathrm{~h}$. The water absorption coefficient is then determined by measuring the water content in the "saturated surface dry" (SSD) state. To achieve the SSD state, saturated sand is exposed to a gentle current of warm air to evaporate surface moisture. The SSD state is identified using a slump test cone. This allows detecting the presence of cohesive forces due to moisture at the particle's surface. This test is performed several times during drying. The metal cone is filled in one single batch and compacted with 25 pestle shots. The SSD state is determined from the shape of the sand pile after lifting the metal cone (Fig. 2). The mass of the sample at the SSD state is recorded. The sample is then dried in an oven at $105{ }^{\circ} \mathrm{C}$ to obtain the dry mass.

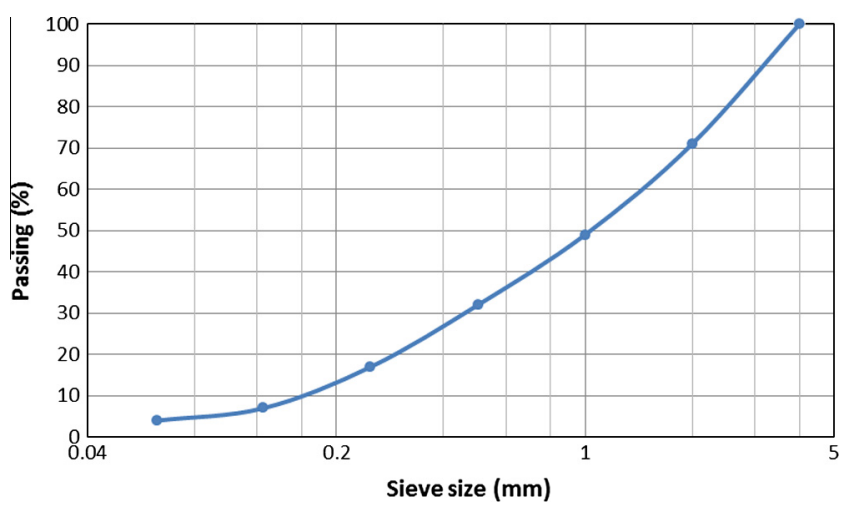

Fig. 1. Particle size distribution of recycled sand.

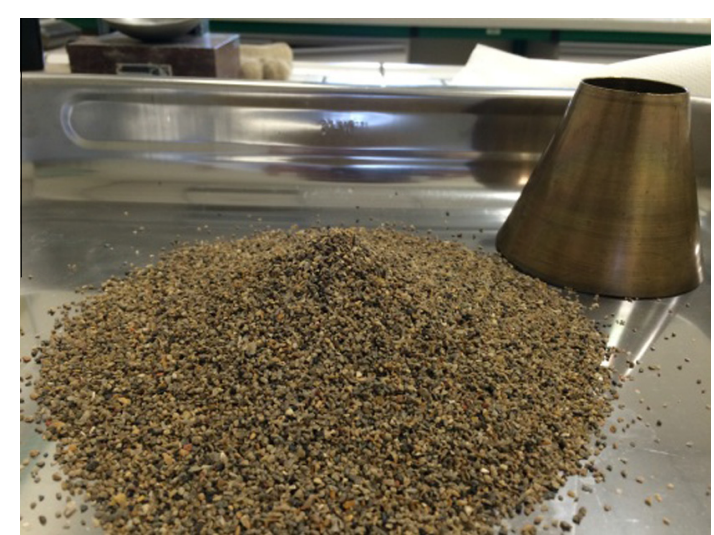

Fig. 2. Shape of cone corresponding to the $\mathrm{SSD}_{\mathrm{EN}}$ state in the standard method EN 1097-6.

\subsubsection{IFSTTAR method $N^{\circ} 78$}

Using this method, the sample is saturated under water for $24 \mathrm{~h}$ as in the standard method EN 1097-6. This procedure is slightly different from the original IFSTTAR method which suggests a pre-saturation during $24 \mathrm{~h}$ with an amount of water equals to WA plus 1 or $2 \%$. The sample is then dried progressively with different sheets of colored absorbent paper until no traces of water can be seen on the paper (Fig. 3). This indication shows that the SSD state was achieved. Drying at $105^{\circ} \mathrm{C}$, as for the standard method, is then carried out to obtain the dry mass of the sample. The water content in the SSD state corresponds to the water absorption coefficient of aggregates.

\subsubsection{Method by extrapolation}

Another method has been developed by Zhao et al. [3] based on the relationship between the cement paste content in the RCA and its water absorption coefficient (equation (1)). This method consists of dividing the recycled sand in different granular classes and measuring, for each class, a quantity proportional to the adherent cement paste content.

$\mathrm{WA}_{\mathrm{GBR}}=\mathrm{WA}_{\mathrm{p}} \mathrm{X}_{\mathrm{p}}+\mathrm{WA}_{\mathrm{GN}}(1-\mathrm{Xp})$

Where:

$\mathrm{WA}_{\mathrm{GBR}}(\%)$ : water absorption coefficient of a given class of RCA.

$\mathrm{WA}_{\mathrm{p}}(\%)$ : water absorption coefficient of adherent cement paste.

$\mathrm{WA}_{\mathrm{GN}}(\%)$ : water absorption coefficient of natural aggregate in RCA.

$\mathrm{Xp}(\%)$ : adherent cement paste content of a given class of RCA.

Eq. (1) shows that there is a linear relationship between the water absorption coefficient of a given class of RCA and its adherent cement paste content (or a quantity that would be proportional to it). This relationship assumes that the water absorption of adherent cement paste and natural aggregate is the same for all granular fractions. This hypothesis is valid only if the immersion time is long enough for water to saturate the whole accessible porosity. Zhao showed that the water absorption coefficients of the coarser classes of the recycled sand (greater than $0.63 \mathrm{~mm}$ ) can be measured satisfactorily with standard or with the IFSTTAR method, which then provide values that are very close. Knowledge of Eq. (1) for the coarse classes is then used to calculate the water absorption coefficients of the finer fractions by extrapolation. Finally, knowing the proportion of each fraction in the sand, the total water absorption coefficient of the sand can be determined.

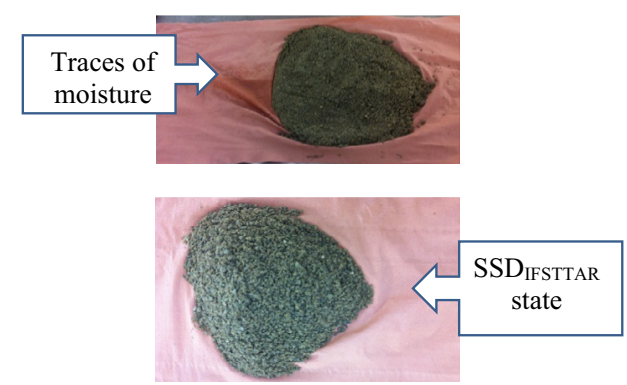

Fig. 3. Traces of water after successive dryings with absorbent paper to identify $\mathrm{SSD}_{\text {IFSTTAR }}$ state in the IFSTTAR method $\mathrm{N}^{\circ} 78$. 
In this study, the RS is divided into 5 granular fractions $(0 / 0.5 \mathrm{~mm} ; 0.5 / 0.8 \mathrm{~mm}$; $0.8 / 1.6 \mathrm{~mm} ; 1.6 / 2.5 \mathrm{~mm} ; 2.5 / 4 \mathrm{~mm}$ ) instead of the 4 fractions used by Zhao et al. [3]. The water absorption coefficient of each fraction and of the complete recycled sand is then measured by the standard method EN 1097-6 and IFSTTAR method N ${ }^{\circ} 78$.

In this extrapolation method, knowing the exact cement paste content is not necessary. The determination of a quantity proportional to the cement paste content is enough. In the original method, the adherent cement paste content was estimated from the soluble fraction in salicylic acid [3]: $0.5 \mathrm{~g}$ of dried representative sample was immersed into a solution of salicylic acid in methanol (14 g of salicylic acid and $80 \mathrm{ml}$ of methanol) and stirred for $1 \mathrm{~h}$ to dissolve the soluble phases of the cement paste. The solution was then filtered to obtain the solid residue. However, this method requires a delicate and highly experienced work. In this study, the adherent cement paste content is estimated from the mass loss between $105^{\circ} \mathrm{C}$ and $475^{\circ} \mathrm{C}$. This simple measurement can be carried out on a larger sample ( $10 \mathrm{~g}$ in our study) and is therefore more representative than the previous one. It gives a quantity proportional to the cement paste content in relation to the dehydration of hydrated phases, except for portlandite which is only partly dehydrated at that temperature. The maximum temperature of $475{ }^{\circ} \mathrm{C}$ has been chosen to avoid the decarbonation of carbonated hydrates that can occur at about $500{ }^{\circ} \mathrm{C}$ as show by Zhao [29] from thermogravimetric analysis (TGA) performed on the same recycled sand.

The measuring of mass loss between $105^{\circ} \mathrm{C}$ and $475{ }^{\circ} \mathrm{C}$ is carried out on at least 5 samples of each granular fraction. The procedure for measuring is the following:

(a) Grind $(d<200 \mu \mathrm{m})$ each fraction of the RS after drying at $70^{\circ} \mathrm{C}$ for $24 \mathrm{~h}$.

(b) Take a representative sample of each fraction ( $10 \mathrm{~g}$ of powder)

(c) Put in oven at $105^{\circ} \mathrm{C}$ for $24 \mathrm{~h}$ and then weigh out sample $\left(M_{105}\right)$.

(d) Set the oven at $475^{\circ} \mathrm{C}$ for $24 \mathrm{~h}$ and then weigh out sample $\left(M_{475}\right)$.

The mass loss ( $\left.\mathrm{ML}_{105-475}\right)$ can then be calculated according to Eq. (2):

$\mathrm{ML}_{105-475}(\%)=\frac{M_{105}-M_{475}}{M_{105}} * 100$

\subsection{Fresh behavior of mortars}

\subsubsection{Materials}

The cement used is an Ordinary Portland Cement CEM II/AL 42,5N EC CP2 NF from the Holcim company plant in Rochefort, provided by the French national project Recybeton. The mineralogical composition is shown in Table 1.

The mortar compositions are shown in Table 2. All the mortars used in this study have the same composition, they only differ in the initial state of saturation of the RS, but the total amount of water present in the mortar is constant. The presaturation method of sand is described below.

\subsubsection{Pre-saturation method}

The RS is first dried at $105{ }^{\circ} \mathrm{C}$ during $24 \mathrm{~h}$. This temperature has been chosen according to the standard method EN 1097-6. Drying the RCA at $105{ }^{\circ} \mathrm{C}$ could lead to the decomposition of some hydrates of the adherent cement paste, particularly ettringite. However, this certainly has a negligible influence on the WA coefficient, given the small amounts of ettringite that are generally present in hydrated Portland cement pastes. Then, $1155 \mathrm{~g}$ of dry RS are introduced into a sealed plastic bottle together with a given quantity of pre-saturation water. This amount of water is noted $W$ in the following and corresponds to the ratio of the mass of pre-saturation water to the mass of dry sand in percent.

Two pre-saturation parameters are studied. Firstly, the amount of water $W$ is fixed at $10 \%$ or $20 \%$ and the pre-saturation time is varied $(1,2,3,7$ and 14 days). The aim is to determine the time needed to reach moisture equilibrium inside the bottle. Then, the pre-saturation time is fixed at 14 days to ensure a moisture equilibrium, and $\mathrm{W}$ is varied from $0 \%$ to $30 \%$. The plastic bottle is stored in an air conditioned room at $20 \pm 2{ }^{\circ} \mathrm{C}$. It is slowly rolled horizontally every two days in order to homogenize the mixture.

\subsubsection{Manufacture of mortars}

The mixing process follows the standard EN 196-1 [31]. The constituents (cement, water, RS) and equipment are stored in an air conditioned room at $20 \pm 2{ }^{\circ} \mathrm{C}$ at least $24 \mathrm{~h}$ before manufacture of the mortars

Table 1

Mineralogical composition of cement determined by XRD-Rietveld analysis according to [30].

\begin{tabular}{llllllll}
\hline & & $\mathrm{C}_{3} \mathrm{~S}$ & $\mathrm{C}_{2} \mathrm{~S}$ & $\mathrm{C}_{3} \mathrm{~A}$ & $\mathrm{C}_{4} \mathrm{AF}$ & Calcite & Gypsum \\
\hline CEM II/A-L 42.5N & $(\%)$ & 53.5 & 12.8 & 4.3 & 13.0 & 10.7 & 3.6 \\
\hline
\end{tabular}

Table 2

Mortar compositions for the investigation of fresh behavior.

\begin{tabular}{lll} 
Recycled sand (RS) & $(\mathrm{g})$ & 1155 \\
Water absorption coefficient & $(\%)$ & 9.0 \\
Cement & $(\mathrm{g})$ & 450 \\
$W_{\text {eff }} / C$ ratio & & 0.73 \\
Effective water & $(\mathrm{g})$ & 104.0 \\
Total water & $(\mathrm{g})$ & 430.5 \\
\hline
\end{tabular}

In this procedure, the time $T_{0}$ corresponds to the time when all the cement has been introduced into mixing water. For the sand used in the dry state, the total amount of water (absorption water and effective water) is introduced into the mixer at $T_{0}$. However, for pre-saturated sands, the amount of water introduced into the mixer corresponds to the total amount of water less the amount of presaturation water introduced into the plastic bottle.

In addition, the mass of each bottle is determined before filling with dry sand and pre-saturation water and after pouring the pre-saturated sand into the mixer. The difference between the two values indicates the amount of sand and water remaining on the walls of the pre-saturation bottle.

\subsubsection{Measurement of workability}

The slump flow of mortars was measured using the CEM cone ("Concrete Equivalent Mortar") in accordance with the procedure developed by Schwartzentruber and Catherine [32] which is shown in Fig. 4. All tests were carried out in an air conditioned room at $20 \pm 2{ }^{\circ} \mathrm{C}$.

The cone is filled in 3 layers of similar volumes, each layer being compacted 15 times with the tamping rod. The top of the cone is then leveled. Given the time needed to place the mortar, the cone is lifted up at about $T_{0}+300 \mathrm{~s}$. The cone is lifted vertically in about $2 \mathrm{~s}$. The slump flow is immediately measured on three diameters with the caliper.

\section{Results and discussion}

\subsection{Water absorption of recycled sand}

\subsubsection{Variation of water absorption and mass loss as function of particle size}

Fig. 5 shows the variation of water absorption obtained with both methods EN 1097-6 and IFSTTAR $\mathrm{N}^{\circ} 78$, as a function of average diameter of each fraction. The water absorption coefficients obtained by the two methods are very similar for the coarse fractions $(d>0.8 \mathrm{~mm})$. However, the difference between the two methods is very important for the fractions lower than $0.8 \mathrm{~mm}$. Indeed, the differences between both methods are much larger than the standard deviation for the two finer fractions.

Fig. 6 shows the variation of mass loss between $105^{\circ} \mathrm{C}$ and $475^{\circ} \mathrm{C}$ as a function of the average diameter of each fraction. It is observed that the mass loss increases as the mean size decreases. A linear relationship between the mass loss and the granular fraction is obtained in the range of selected classes. This result confirms the results obtained by Zhao et al. [3] with a measurement of the cement paste content from the soluble fraction in salicylic acid.

The water absorption coefficient should normally increase linearly when particle size decreases because the smaller particles possess more adherent cement paste (Fig. 6). But in the Fig. 5, with the standard method EN 1097-6, we observe a decrease in absorption with fraction $0 / 0.5 \mathrm{~mm}$. The standard method does not allow accurately measuring the water absorption of fine fractions. Indeed, for very small angular particles (such as those obtained from crushed concrete), the recycled sand may have some cohesion, even if all the water at the surface of particles has been eliminated, preventing the complete collapse of the cone. The standard method EN 1097-6 therefore certainly underestimates the water absorption for finer fractions [3]. On the contrary, the IFSTTAR method $N^{\circ} 78$ gives a very high value of water absorption for the finer fraction. This result is due to the fact that very small particles tend to agglomerate during drying, due to capillary forces. The absorbent paper dries the surface of the agglomerates, but it does not break them. The IFSTTAR method $\mathrm{N}^{\circ} 78$ therefore 

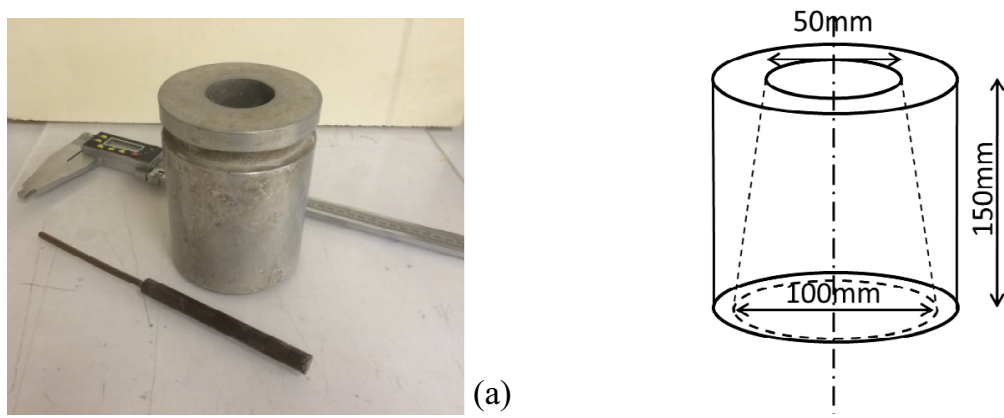

(b)

(a) Equipment used to measure the workability of mortar

(b) Dimensions of CEM cone

(c) Example of measuring slump flow (measurement of three diameters)

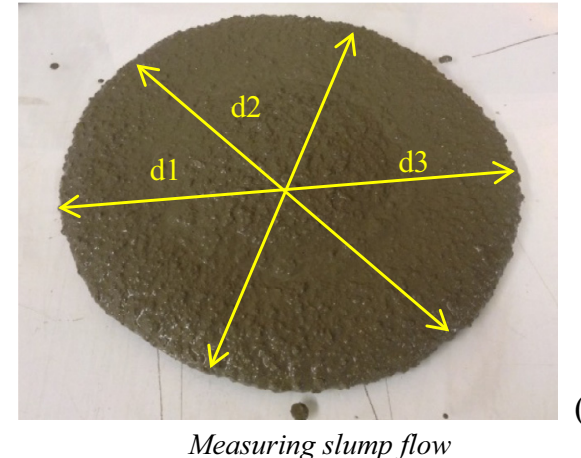

(c)

Fig. 4. Slump flow test of mortar with CEM cone.

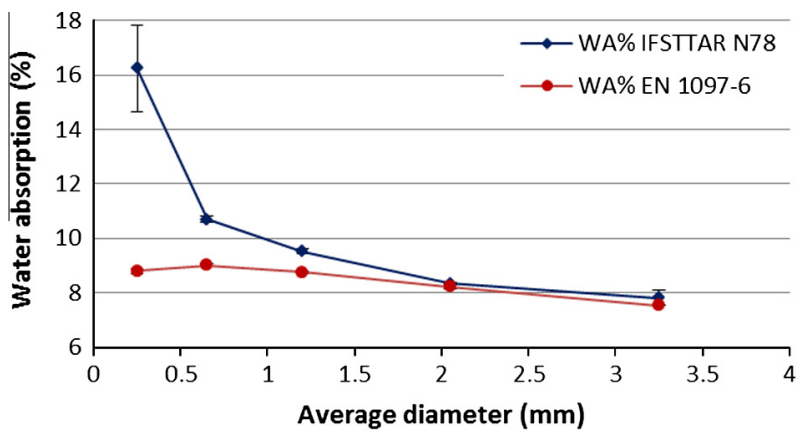

Fig. 5. Water absorption of different fractions of RS (error bars correspond to \pm the standard deviation).

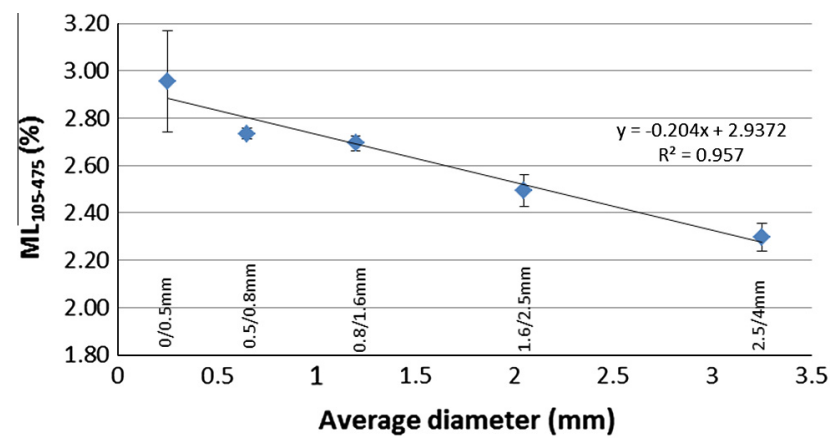

Fig. 6. Mass loss between $105{ }^{\circ} \mathrm{C}$ and $475{ }^{\circ} \mathrm{C}$ of different fractions of recycled sand (error bars correspond to \pm the standard deviation).

overestimates the water absorption coefficient of the fine fractions [3]. Two types of water can therefore be distinguished in this case: water that is really absorbed by aggregates and water that is trapped inside agglomerates (interstitial water).

\subsubsection{Extrapolation method}

Assuming a linear relationship between the mass loss and the granular fraction $\left(X_{\mathrm{p}}=k * \mathrm{ML}_{105-475}\right)$, we obtain from Eq. (1):

$\mathrm{WA}_{\mathrm{GBR}}=\left(\mathrm{WA}_{\mathrm{p}}-\mathrm{WA}_{\mathrm{GN}}\right) k \mathrm{ML}_{105-475}+\mathrm{WA}_{\mathrm{GN}}$

Fig. 7 shows the correlation between the mass loss and water absorption (standard method EN 1097-6 and IFSTTAR method N ${ }^{\circ} 78$ ) of the three coarse fractions. It is observed that when the mass loss increases, the water absorption also increases. In addition, the water absorption varies linearly with mass loss. With Eq. (2), knowing the mass loss of the fine fractions, the previous linear relationship can be extrapolated to find the water absorption of the fine fractions. The extrapolated values are shown in Table 3. The values obtained by the two methods are very similar for both finer fractions.

Then, knowing the proportion of each fraction in the recycled sand, the total water absorption coefficient of the recycled sand can be determined. The results are presented in Table 3. The two values are close (respectively $8.7 \%$ and $9.1 \%$ from the extrapolation of standard and IFSTTAR methods). Table 4 shows the water absorption coefficients of recycled sand $(0 / 4 \mathrm{~mm})$ obtained from different methods.

Fig. 5 has shown that the WA coefficients measured on each of the three coarser fractions with EN 1097-6 and IFSTTAR methods were very close. This suggests that, for coarse particles (larger than or equal to about $0.8 \mathrm{~mm}$ ), the two methods are able to identify satisfactorily the SSD state. However, for the finer fractions, the two methods diverge significantly, showing that the presence of fine particles prevents an accurate identification of SSD state. As the extrapolation method only necessitates the measurement of WA of coarse fractions, and the determination of mass loss of all fractions, we think that this method is more accurate than EN and IFSTTAR methods performed on the entire $0-4 \mathrm{~mm}$ fraction of sand. Indeed, in the Table 4, the WA values obtained on the fraction $0-4 \mathrm{~mm}$ by the standard EN 1097-6 and IFSTTAR methods are very different (respectively 7.3 and $10.6 \%$ ). On the contrary, using the extrapolation method, the values of two extrapolated 


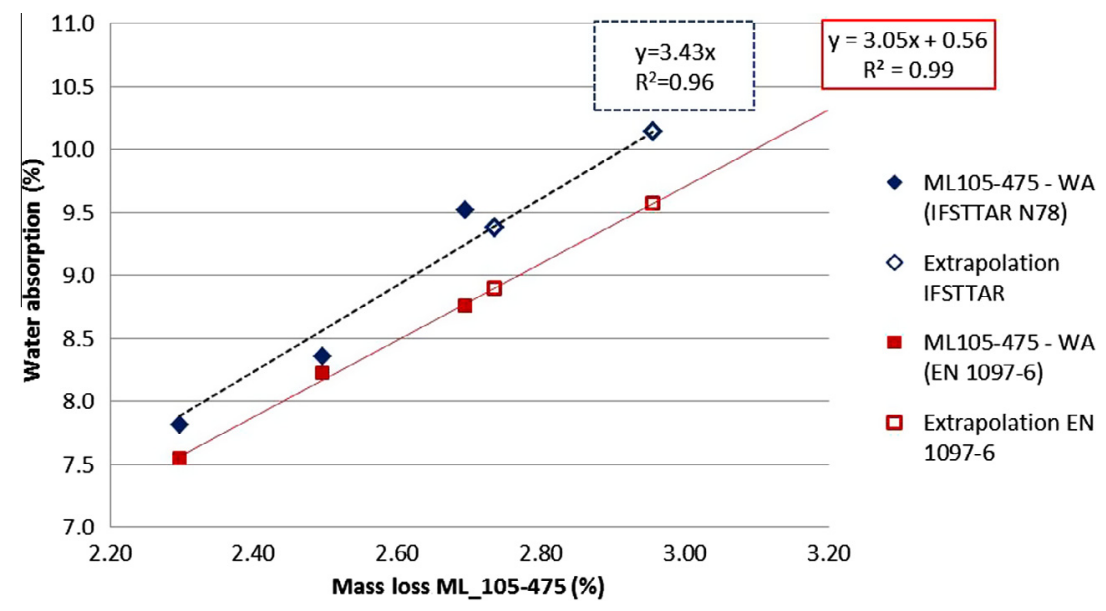

Fig. 7. Correlation between the mass loss and water absorption of different fractions of RS.

Table 3

Extrapolation of water absorption of the fine fractions.

\begin{tabular}{|c|c|c|c|c|c|c|}
\hline Granular fraction & $2.5-4 \mathrm{~mm}$ & $1.6-2.5 \mathrm{~mm}$ & $0.8-1.6 \mathrm{~mm}$ & $0.5-0.8 \mathrm{~mm}$ & $0-0.5 \mathrm{~mm}$ & WA of RS (\%) $0 / 4 \mathrm{~mm}$ \\
\hline Proportion (\%) & 20 & 18 & 20 & 12 & 30 & \\
\hline Mass loss $\mathrm{ML}_{105-475}(\%)$ & 2.30 & 2.50 & 2.69 & 2.73 & 2.96 & \\
\hline WA (\%) (EN 1097-6) & 7.5 & 8.2 & 8.8 & 8.9 & 9.6 & 8.7 \\
\hline \multirow[t]{2}{*}{ WA (\%) (IFSTTAR N78) } & 7.8 & 8.4 & 9.5 & 9.4 & 10.1 & 9.1 \\
\hline & & & & Extrapolated value WA & Extrapolated value WA & Calculated value WA \\
\hline
\end{tabular}

Bold values indicate extrapolated or calculated values of WA.

Table 4

Water absorption coefficients of recycled sand $(0 / 4 \mathrm{~mm})$ obtained from different methods.

\begin{tabular}{lllll}
\hline Method & EN & $\begin{array}{l}\text { Extrapolation EN } \\
1097-6\end{array}$ & $\begin{array}{l}\text { IFSTTAR } \\
\mathrm{N}^{\circ} 78\end{array}$ & $\begin{array}{l}\text { Extrapolation } \\
\text { IFSTTAR }\end{array}$ \\
\hline WA (\%) & 7.3 & 8.7 & 10.6 & 9.1 \\
Standard & 0.5 & & 0.1 & \\
$\quad$ deviation (\%) & & & & \\
\hline
\end{tabular}

WA coefficients obtained with EN 1097-6 and IFSTTAR methods are much closer (8.7 and 9.1\%).

\subsection{Fresh behavior of mortars}

3.2.1. Workability as a function of pre-saturation time

The influence of pre-saturation time on the workability of mortars has been studied with the saturation mode in plastic bottle for

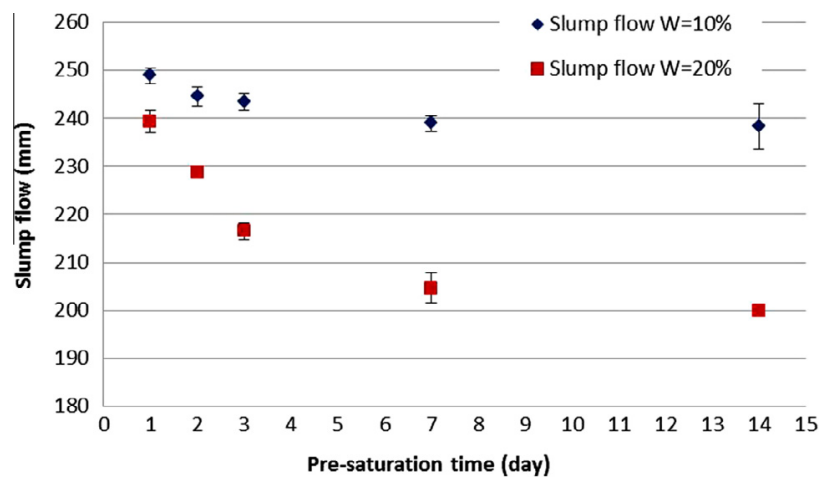

Fig. 8. Workability of mortar as a function of pre-saturation time (error bars correspond to \pm the standard deviation).
$1,2,3,7$ and 14 days with a pre-saturation water content corresponding to $W=10 \%$ and $20 \%$. Fig. 8 shows the variation of slump flow of mortars as a function of pre-saturation time for $W=10$ and $20 \%$. This figure shows that the slump flow decreases when the pre-saturation time increases. A stabilization of slump flow can be found from 7 days of pre-saturation. It is also observed that, with a water content $W=10 \%$, the variation of slump flow is smaller than with $W=20 \%$. These results can be attributed to the absorption kinetics of RS. With an increase in pre-saturation time, the absorbed water by the aggregates increases. The free water in the mixture available for the workability therefore decreases because the total water used in all mixtures is identical. The plateau of slump flow is found when the amount of free water in the mixture is constant; meaning that aggregates cannot absorb any more water (or the aggregates are saturated). In this state, it can be assumed that moisture in the pre-saturation bottle is homogeneously distributed among aggregate particles.

\subsubsection{Workability as a function of pre-saturation water content}

Fig. 9 shows the variation of the slump flow of mortars and the residual mass in the pre-saturation bottles as a function of the pre-saturation water content. It is observed in this figure that the slump flow of mortars decreases when the amount of presaturation water increases. There is a significant loss of slump flow between 9 and 11\%. Beyond this content, the slump flow loss slows down. Finally there is a first slump flow plateau at $W=14 \%$ and another at $W=18 \%$. Some of the results presented in Fig. 9 have been reproduced twice (in green in the figure) and show a good reproducibility of the tests. Moreover, some preliminary tests performed with another recycled sand and with a lower $W_{\text {eff }} / C$ ratio have also shown the same tendency.

When the sand is used in the dry state, all the effective water and water absorption are added into the mixer at the same time. The amount of water available for fluidizing the mixture is maximal and the slump flow is the highest. 


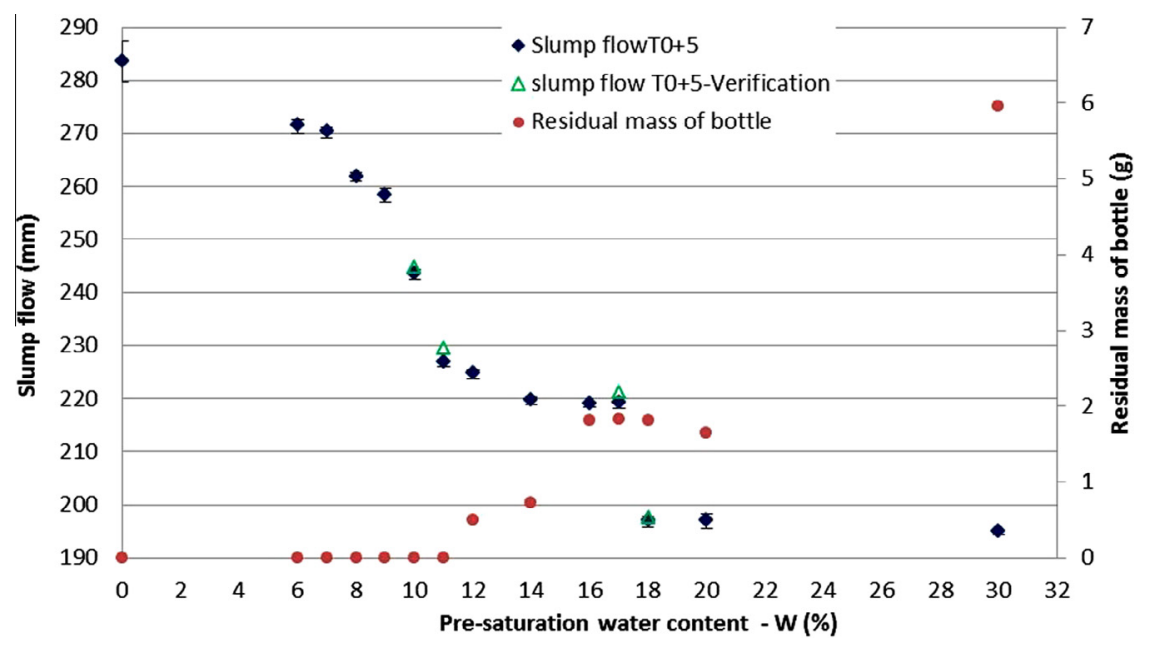

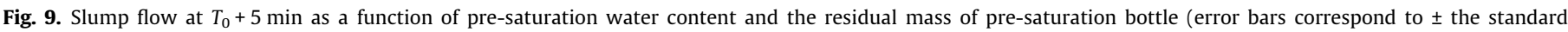
deviation).

When the pre-saturation water increases, a part of water is absorbed by the aggregates, therefore the amount of water available for fluidizing the mixture is decreased and it is lower than in the mortar made with dry sand. The workability is consequently decreased. When the aggregates are completely saturated, water available for fluidizing the mixture must remain constant, as well as the slump flow of mortar. A plateau of slump flow should in that case be observed. However, we cannot consider that all of the pre-saturation water is absorbed by the aggregates. Indeed in the pre-saturation bottle, part of the water is present in the pores of aggregates (absorbed water) and another in agglomerates of small particles (interstitial water).

The plateau of slump flow observed in Fig. 9 from $W=14 \%$ could be attributed to a complete saturation of RS. However, a second plateau of slump flow is observed from $W=18 \%$. This second stage could not be explained yet. It could be attributed to a chemical effect due to the dissolution of ions from the adherent cement paste in the excess pre-saturation water that could modify the rheology of mortars. This hypothesis remains to be verified.

Fig. 9 also shows that we have no residual mass in presaturation bottle until $W=11 \%$. The residual mass is then increased slightly between $11 \%$ and $14 \%$, then a significant increase is observed for $W=16 \%$. Above this value, the residual mass remains approximately constant, except for $W=30 \%$, due to a larger amount of pre-saturation water. This residual mass indicates the presence of capillary forces which stick a part of the wet sand on the walls of the bottle

Here, this result could be compared with the American standard ASTM C128-04 [33]. In this standard, the SSD state of a sand rich of fine particles is evaluated by depositing the wet sand on a flat, dry, clean and non-absorbent surface to detect traces of moisture. The later indicates the moisture state of sand particles. These residual mass results therefore suggest that, at least until $W=11 \%$, all the pre-saturated water could be absorbed in the internal porosity of the particles.

The residual mass results suggest that, for the pre-saturation mode used, the water absorption coefficient of RS could be $11 \%$ This value is significantly higher than that previously obtained with the extrapolation method. It can be assumed here that saturation vapor, such as that prevailing in the bottle, leads to a more complete saturation of the internal porosity than with a complete immersion in water, which may trap part of the air in porosity.

From these results, we decided to measure the water absorption of the RS using the extrapolation method with a saturation of RS in plastic bottle. The three coarse fractions $(d>0.8 \mathrm{~mm})$ have been pre-saturated in plastic bottles with a pre-saturation water content $W=12 \%$ for 14 days. The water absorption of each fraction has been measured by two methods: EN 1097-6 and IFSTTAR method $N^{\circ} 78$. The experimental and extrapolated results are shown in Table 5. A little increase in WA with the saturation mode in plastic bottle (9.4\% and 9.5\% respectively obtained by EN 1097-6 and IFSTTAR methods) can be observed in comparison to that obtained with the saturation mode under water $(8.7 \%$ and $9.1 \%$ respectively obtained by EN 1097-6 and IFSTTAR methods). But this value is much lower than the one obtained from the residual mass (11\%).

The larger value obtained from the residual mass of bottles in comparison to WA (11\% instead of $9.5 \%$ ) could be due to the presence of agglomerates of fine particles in the bottles, during the pre-saturation stage, due to capillary forces. Indeed, if these agglomerates are stable enough, they might persist during the presaturation stage. When the RS sand is incorporated into the mixer, the water trapped into agglomerates could be released and participate to the workability of the mortar. Therefore, these agglomerates could lead to a shift of the curve toward larger water content values.

In order to confirm the presence of agglomerates during the pre-saturation of RS in bottles, a comparison of the particle size distributions (PSD) of the RS before and after pre-saturation has been carried out. A first PSD has been measured on the dry sand with the following sieves: $2.5 \mathrm{~mm}, 1.6 \mathrm{~mm}, 0,8 \mathrm{~mm}$ and $0.5 \mathrm{~mm}$. Then, a second PSD has been measured on the RS after two weeks of pre-saturation in a bottle with $W=11 \%$. The proportion of each fraction is presented in Fig. 10. It is observed that the PSD of RS has changed a lot after pre-saturation. The proportion of fraction lower than $0.5 \mathrm{~mm}$ decreased from $30 \%$ to $11 \%$ after pre-saturation. On the contrary, the proportion of the other fractions increased significantly. This result confirms that pre-saturation water leads to the formation of agglomerates of fine particles $(<0.5 \mathrm{~mm})$. The surface of these agglomerates might be dry after two weeks of pre-saturation, which could explain that the residual mass of the bottles up to $W=11 \%$ remains null. However, the quantity of water that they contain does not correspond to absorbed water; it can be re-mobilized in the mixer and participate to the workability of the mortar.

\section{Conclusions}

Two methods were implemented to determine the water absorption coefficient of the whole recycled sand (fraction $0-4 \mathrm{~mm}$ ) and of five different fractions. The values of water absorption coefficients obtained for the whole sand are highly 
Table 5

Extrapolation of water absorption of the fine fractions with the pre-saturation mode in the plastic bottle ( $W=12 \%$ for 14 days).

\begin{tabular}{|c|c|c|c|c|c|c|}
\hline Granular fraction & $2.5-4 \mathrm{~mm}$ & $1.6-2.5 \mathrm{~mm}$ & $0.8-1.6 \mathrm{~mm}$ & $0.5-0.8 \mathrm{~mm}$ & $0-0.5 \mathrm{~mm}$ & WA RS 0/4 mm (\%) \\
\hline Proportion (\%) & 20 & 18 & 20 & 12 & 30 & \\
\hline Mass loss $\mathrm{ML}_{105-475}(\%)$ & 2.30 & 2.50 & 2.69 & 2.73 & 2.96 & \\
\hline WA (\%) (EN 1097-6) & 8.1 & 8.5 & 9.7 & 9.7 & 10.6 & 9.4 \\
\hline \multirow[t]{2}{*}{ WA (\%) (IFSTTAR N78) } & 8.0 & 8.5 & 9.8 & 9.9 & 10.9 & 9.5 \\
\hline & & & & Extrapolated value WA & Extrapolated value WA & Calculated value WA \\
\hline
\end{tabular}

Bold values indicate extrapolated or calculated values of WA.

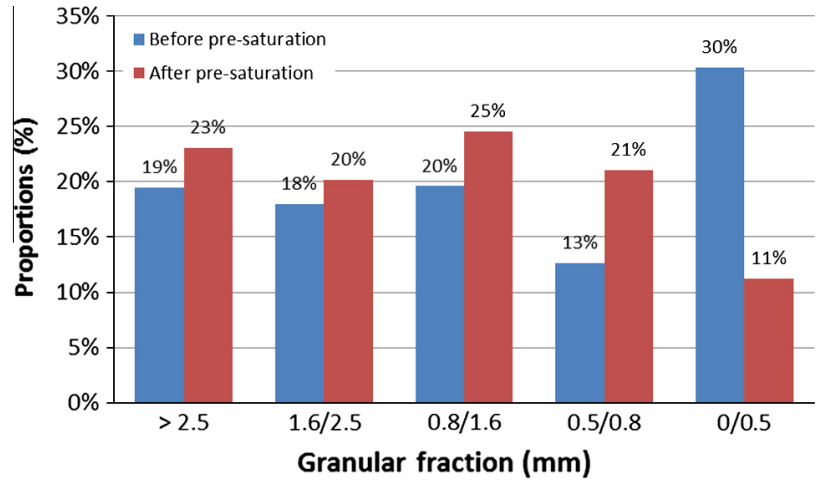

Fig. 10. Proportion of each granular fraction before and after pre-saturation with $W=11 \%$ for 2 weeks.

dependent on the method used. In particular, the standard method EN 1097-6 seems to underestimate the water absorption coefficient while the IFSTTAR $N^{\circ} 78$ method overestimates it. However, when these two methods are applied on the coarser fractions of sand (larger than or equal to $0.8 \mathrm{~mm}$ ) the water absorption coefficients obtained for each are very close.

Using the extrapolation method, an indirect method, the absorption coefficient of the finer fractions is determined from that of coarser ones. Then the water absorption coefficient of whole recycled sand is determined from the proportions and water absorptions of each fraction. By comparing all results, this method seems more accurate than EN and IFSTTAR methods performed on the entire $0-4 \mathrm{~mm}$ fraction of sand. The WA coefficient of recycled sand obtained in our case with this method is of about $9 \%$ with the saturation mode under water.

There is a large influence of the pre-saturation time on the workability of the mortar. The workability of mortar manufactured with pre-saturated sand in the bottle is identical when the pre-saturation time is longer than 7 days. Hence, the time necessary to obtain a moisture equilibrium in the pre-saturation bottle is above 7 days.

There is also a significant influence of the saturation state of the recycled sand on the workability of the mortar. With a constant composition (including total constant water), the workability of mortar made with dry sand is higher than that of mortars made with wet sand. A plateau of workability is obtained when the aggregate is completely saturated. However, the value of presaturation content corresponding to this point could not be considered as the WA value. Indeed in the pre-saturation bottle, the water is present both as absorbed water but also as interstitial water. It has been shown that agglomerates of fine particles are formed in the pre-saturation bottle even if the pre-saturation water content is lower than $11 \%$.

\section{Acknowledgments}

The authors thank the National Project RECYBETON and ANR ECOREB which supported this research.

\section{References}

[1] G.A. Blengini, E. Garbarino, S. Šolar, D.J. Shields, T. Hámor, R. Vinai, Z. Agioutantis, Life Cycle Assessment guidelines for the sustainable production and recycling of aggregates: the Sustainable Aggregates Resource Management project (SARMa), J. Clean. Prod. 27 (May) (2012) 177-181.

[2] T.-D. Nguyen, G. Le Saout, P. Devillers, E. Garcia-Diaz, The effect of limestone aggregate porosity and saturation degree on the interfacial zone, in: the 2nd International Symposium on Cement-based Materials for Nuclear Wastes, 2014, p. 13.

[3] Z. Zhao, S. Remond, D. Damidot, W. Xu, Influence of hardened cement paste content on the water absorption of fine recycled concrete aggregates, J. Sustain. Cem. Mater. 2 (3-4) (2013) 186-203.

[4] Z. Zhao, S. Remond, D. Damidot, W. Xu, Influence of fine recycled concrete aggregates on the properties of mortars, Constr. Build. Mater. 81 (2015) 179186.

[5] M. Etxeberria, E. Vázquez, A. Marí, M. Barra, Influence of amount of recycled coarse aggregates and production process on properties of recycled aggregate concrete, Cem. Concr. Res. 37 (5) (2007) 735-742.

[6] M.S. de Juan, P.A. Gutiérrez, Study on the influence of attached mortar content on the properties of recycled concrete aggregate, Constr. Build. Mater. 23 (2) (2009) 872-877.

[7] C.S. Poon, S.C. Kou, L. Lam, Use of recycled aggregates in molded concrete bricks and blocks, Constr. Build. Mater. 16 (5) (2002) 281-289.

[8] K. Eguchi, K. Teranishi, A. Nakagome, H. Kishimoto, K. Shinozaki, M. Narikawa, Application of recycled coarse aggregate by mixture to concrete construction, Constr. Build. Mater. 21 (7) (2007) 1542-1551.

[9] L. Evangelista, J. de Brito, Mechanical behaviour of concrete made with fine recycled concrete aggregates, Cem. Concr. Compos. 29 (5) (2007) 397-401.

[10] J.M.V. Gómez-Soberón, Porosity of recycled concrete with substitution of recycled concrete aggregate: an experimental study, Cem. Concr. Res. 32 (8) (2002) 1301-1311.

[11] C.S. Poon, Z.H. Shui, L. Lam, H. Fok, S.C. Kou, Influence of moisture states of natural and recycled aggregates on the slump and compressive strength of concrete, Cem. Concr. Res. 34 (1) (2004) 31-36.

[12] İ.B. Topçu, S. Şengel, Properties of concretes produced with waste concrete aggregate, Cem. Concr. Res. 34 (8) (2004) 1307-1312.

[13] J. Xiao, J. Li, C. Zhang, Mechanical properties of recycled aggregate concrete under uniaxial loading, Cem. Concr. Res. 35 (6) (2005) 1187-1194.

[14] C.S. Poon, L. Lam, S.C. Kou, Influence of recycled aggregate on slump and bleeding of fresh concrete, Mater. Struct. 40 (2007) 981-988.

[15] V. Corinaldesi, Mechanical and elastic behaviour of concretes made of recycledconcrete coarse aggregates, Constr. Build. Mater. 24 (9) (2010) 1616-1620.

[16] B. Mas, A. Cladera, T. Del Olmo, F. Pitarch, Influence of the amount of mixed recycled aggregates on the properties of concrete for non-structural use, Constr. Build. Mater. 27 (1) (2012) 612-622.

[17] W.H. Kwan, M. Ramli, K.J. Kam, M.Z. Sulieman, Influence of the amount of recycled coarse aggregate in concrete design and durability properties, Constr. Build. Mater. 26 (1) (2011) 565-573.

[18] M. Malešev, V. Radonjanin, S. Marinković, Recycled concrete as aggregate for structural concrete production, Sustainability 2 (5) (2010) 1204-1225.

[19] M. Braga, J. De Brito, R. Veiga, Incorporation of fine concrete aggregates in mortars, Constr. Build. Mater. 36 (2012) 960-968.

[20] I. Vegas, I. Azkarate, A. Juarrero, M. Frías, Design and performance of masonry mortars made with recycled concrete aggregates, Mater. Constr. 59 (295) (2009) 5-18.

[21] V. Corinaldesi, M. Giuggiolini, G. Moriconi, Use of rubble from building demolition in mortars, Waste Manage. 22 (8) (2002) 893-899.

[22] V. Corinaldesi, Mechanical behavior of masonry assemblages manufactured with recycled-aggregate mortars, Cem. Concr. Compos. 31 (7) (2009) 505-510.

[23] V. Corinaldesi, G. Moriconi, Influence of mineral additions on the performance of 100\% recycled aggregate concrete, Constr. Build. Mater. 23 (8) (2009) 28692876.

[24] S.T. Lee, Influence of recycled fine aggregates on the resistance of mortars to magnesium sulfate attack, Waste Manage. 29 (8) (2009) 2385-2391.

[25] A.Z. Bendimerad, E. Roziere, A. Loukili, Combined experimental methods to assess absorption rate of natural and recycled aggregates, Mater. Struct. (2014).

[26] A. Djerbi Tegguer, Determining the water absorption of recycled aggregates utilizing hydrostatic weighing approach, Constr. Build. Mater. 27 (1) (2012) $112-116$. 
[27] NF EN 1097-6, Tests for mechanical and physical properties of aggregatespart 6: determination of particle density and water absorption, 2001, p. 34.

[28] IFSTTAR, Test Method No. 78:2011. Tests on aggregates for concrete: measurement of total water absorption by a crushed sand, Paris, 2011.

[29] Z. Zhao, Re-use of Fine Recycled Concrete Aggregates for the Manufacture of Mortars, University of Lille, 2014. p. 1.

[30] G. Le Saoût, V. Kocaba, K. Scrivener, Application of the Rietveld method to the analysis of anhydrous cement, Cem. Concr. Res. 41 (2) (2011) 133-148.
[31] EN 196-1, Methods of testing cement - Part 1: Determination of strength, European Committee for Standardization, 2006.

[32] A. Schwartzentruber, C. Catherine, Method of the concrete equivalent morta (CEM) - a new tool to design concrete containing admixture, Mater. Struct. 33 (2000) 475-482.

[33] ASTM C128-04, Standard Test Method for Density, Relative Density (Specific Gravity), and Absorption of fine aggregate, no. August, 2004, pp. 1-6. 